\title{
The genetics of gestational diabetes mellitus: evidence for relationship with type 2 diabetes mellitus
}

Julie Robitaille, $P h D^{1}$, and Althea M. Grant, $P h D^{2}$

\begin{abstract}
Gestational diabetes is a major public health problem because of its prevalence, its associated complications during pregnancy, and its increased risk for type 2 diabetes later in life. Insulin resistance is one of many physiological changes occurring during pregnancy, and when insulin resistance is accompanied by pancreatic $\beta$-cell insufficiency, gestational diabetes may develop. Several lines of evidence suggest that gestational diabetes shares a common etiology with type 2 diabetes and support the hypothesis that gestational diabetes serves as a window to reveal a predisposition to type 2 diabetes. Pregnancy is an environmental stressor that may catalyze the progression to a diabetic state in genetically predisposed women; therefore, identification of these women during pregnancy could decrease the occurrence of type 2 diabetes through targeted prevention. This review presents an overview of the genetics of gestational diabetes, focusing on human association studies with candidate genes common to both type 2 diabetes and gestational diabetes. Genet Med 2008:10(4):240-250.
\end{abstract}

Key Words: gestational diabetes mellitus, type 2 diabetes, genetics, pregnancy, association studies

Gestational diabetes mellitus (GDM) is a major public health problem because of its prevalence and its associated complications during pregnancy. It is estimated that $4 \%$ of pregnancies in the United States are complicated by GDM, although the prevalence of GDM varies considerably among racial and ethnic groups. ${ }^{1}$ Uncontrolled GDM increases the risk of adverse neonatal outcomes such as macrosomia, birth injuries, neonatal hypoglycemia, neonatal cardiac dysfunction, and stillbirth. ${ }^{2}$ In addition to increasing the risk of adverse infant outcomes, GDM also has high predictive value for later development of type 2 diabetes (T2D) in the mother and in her offspring. Women who experience GDM have increased risk of developing T2D after pregnancy, ranging from $17 \%$ to $63 \%$ within 5-16 years after pregnancy depending on the population and other risk factors. ${ }^{3}$ Additionally, offspring of mothers with GDM are more likely to be obese and display impaired glucose tolerance during adolescence than are offspring of

From the ${ }^{1}$ National Center on Birth Defects and Developmental Disabilities; and ${ }^{2}$ National Center on Birth Defects and Developmental Disabilities, Division of Blood Disorders, Centers for Disease Control and Prevention, Atlanta, Georgia.

Althea M. Grant, PhD, Division of Blood Disorders, National Center for Birth Defects and Developmental Disabilities, Centers for Disease Control and Prevention, 1600 Clifton Road, MS E64, Atlanta, GA 30333. E-mail: AGrant@cdc.gov.

The findings and conclusions in this report are those of the authors and do not necessarily represent the view of the Centers for Disease Control and Prevention.

Disclosure: The authors declare no conflict of interest.

Supplementary tables are available via the ArticlePlus feature at www.geneticsinmedicine.org. Please go to the April issue and click on the ArticlePlus link posted with the article in the Table of Contents to view this material.

Submitted for publication October 3, 2007.

Accepted for publication January 8, 2008.

DOI: 10.1097/GIM.0b013e31816b8710 nondiabetic mothers. Thus, diabetes during pregnancy is not only associated with the later risk of diabetes in mothers but also with metabolic changes that may lead to the development of diabetes in their offspring. ${ }^{4}$ This observed connection between GDM and risk of T2D strongly suggests that GDM can serve as a window revealing a predisposition to $\mathrm{T} 2 \mathrm{D}$, with pregnancy as the environmental stressor that catalyzes progression to a diabetic state in predisposed individuals. ${ }^{5}$

Several lines of evidence support the above hypothesis. First, GDM shares several risk factors with T2D, including high body mass index (BMI), history of abnormal glucose tolerance, diabetes in a first-degree relative, and membership in an ethnic group with a high risk of T2D. ${ }^{6}$ Second, GDM and T2D share similar pathophysiologies: women undergo major physiological changes during pregnancy that allow the fetus to survive and thrive in the intrauterine environment. One important physiological change that occurs in normal pregnancies is an increase in insulin resistance throughout pregnancy. ${ }^{6}$ By late pregnancy, women's insulin sensitivity has declined to one third that of their nonpregnant state. This increased insulin resistance facilitates continuous glucose transfer to the fetus. However, when insulin resistance is accompanied by pancreatic $\beta$-cell insufficiency, GDM may develop. ${ }^{7}$ The pathophysiological changes of GDM are similar to those observed in T2D, which is also characterized by peripheral insulin resistance accompanied by an insulinsecretory defect.

Evidence is also accumulating that susceptibility to GDM much like T2D-has a genetic component. Although no studies have specifically evaluated the heritability of GDM, evidence suggests that GDM aggregates within families and is associated 
with a history of T2D. Williams et al. ${ }^{8}$ observed that the risk of GDM was positively associated with parental history of T2D. Women with any parental history of diabetes, compared with women with nondiabetic parents, experienced a 2.3-fold increased risk of GDM. ${ }^{8}$ Additionally, women with a diabetic sibling had an 8.4-fold higher risk of GDM than women with no diabetic siblings. ${ }^{8}$ The heritability of GDM is complicated, however, by accumulating evidence suggesting that the predisposition to GDM may be at least partly attributable to epigenetic changes caused by prenatal exposure to a diabetic intrauterine environment. For instance, Martin et al. ${ }^{9}$ observed that GDM was eight times more frequent in the mothers of women who have GDM than in the mothers of the "controls"; by contrast, the incidence of diabetes was the same in the fathers of both groups. Similarly, Harder et al. ${ }^{10}$ found that among women with GDM, noninsulin-dependent diabetes mellitus (NIDDM) was more prevalent in their mothers than their fathers, and more common on the maternal grandmaternal side than on the paternal grandpaternal side. By contrast, in patients with IDDM no significant difference concerning the prevalence of any type of diabetes between mothers and fathers was observed. These findings suggest some unique aspects of family history in GDM that deserve further inquiry and detailed examination beyond the scope of this review.

Genetic studies of T2D suggest that it is a multigenic disease in which common variants in multiple genes interact with environmental factors to cause the disease. ${ }^{11-13}$ Because of the striking parallels between GDM and T2D, it is likely that GDM is also a multigenic disease related to T2D. Thus, recent work on the etiology of GDM has begun to evaluate the role of common variants in genes predisposing to T2D. This article provides a review of genetic variations evaluated for an association with GDM, focusing on genetic markers that are common to both GDM and T2D. The ability to identify pregnant women with a genetic predisposition to develop T2D later in life will enable the use of targeted prevention strategies, including lifestyle modifications, to prevent or delay the onset of this condition. Additionally, identification of gene variants linked to GDM will contribute to understanding the pathophysiology of GDM and, eventually, developing interventions for its prevention.

\section{MATERIALS AND METHODS}

A search of the PubMed database was performed to retrieve articles addressing the genetics of GDM published between January 1, 1980, and September 1, 2007. The following keywords were used: GDM, T2D, insulin resistance, pregnancy, $\beta$-cell genetics, NIDDM, in combination with genetics, polymorphisms, and gene. Articles examining the association between GDM and genetic variants were abstracted, focusing on genetic markers common to both GDM and T2D. Nonfamilial cross-sectional, case-control, and cohort studies were eligible for inclusion. Based on these selection criteria, 22 genetic association studies were included in the review. Thirteen studies were excluded for the following reasons: GDM was not the primary outcome, family-based studies, control group not ap- propriate for case-control studies (e.g., individuals with NIDDM as controls), no subjects' characteristics available. We also excluded studies reporting associations between GDM and genes from the HLA complex, because these genes are more closely linked to type 1 diabetes than to T2D and have been reviewed elsewhere. ${ }^{14}$

\section{RESULTS OF DATABASE SEARCH: GENES ASSOCIATED WITH GDM}

The following section reviews studies of genetic variants associated with GDM. These variants have been grouped as (a) insulin secretion genes; (b) insulin and insulin signaling genes; (c) lipid and glucose metabolism genes; (d) maturity-onset diabetes of the young (MODY) genes; and (e) other genes. A summary of these studies is presented in Table 1 (available online only). Table 2 (available online only) provides a description of the GDM-associated genes and their functions.

\section{Insulin secretion genes}

\section{$\beta$-Cell $K_{\text {ATP }}$ channel}

The $\beta$-cell $\mathrm{K}_{\mathrm{ATP}}$ channel is composed of two subunits: the potassium inwardly rectifying channel, subfamily J, member 11 (KCNJ11), and the sulfonylurea receptor 1 (ABCC8). The flux of $\mathrm{K}^{+}$ions, and therefore the electrical activity of cell membranes, is regulated by the $\mathrm{K}_{\mathrm{ATP}}$ channels. Release of insulin by $\beta$-cells is initiated by this electrical activity, and thus, is dependent on the function of $\mathrm{K}_{\mathrm{ATP}}$ channels. ${ }^{15}$

Several mutations within the $A B C C 8$ gene have been associated with hyperinsulinemia of infancy. ${ }^{15}$ More common variations within this gene have also been studied in relation to T2D. Among them, the $-3 \mathrm{~T}$ allele of the exon $16-3 \mathrm{C}>\mathrm{T}$ splice acceptor site variant has been associated with $\beta$-cell dysfunction as well as with an increased risk of T2D. ${ }^{16-19}$ Another variant, the Arg1273Arg $(A>G)$, has been associated with T2D-related phenotypes such as hyperinsulinemia in nondiabetic Mexican Americans. ${ }^{20}$

Only one study, to our knowledge, examined the relationship between GDM and variants within the $A B C C 8$ gene. Rissanen et al. ${ }^{19}$ examined eight variants identified by molecular screening of the gene in 42 Finnish patients with GDM. Among the variants examined, the exon $16-3 \mathrm{~T}$ allele and the $1273 \mathrm{G}$ allele of the Arg1273Arg variant were more frequent in women with GDM compared with 377 control subjects (55.0\% vs. $43.0 \%, P=0.024$ and $87.0 \%$ vs. $74.0 \%, P=$ 0.009 , respectively). No significant difference in allele frequency was observed for the other variants identified. Despite these associations with GDM, these variants were not associated with variations in insulin secretion as demonstrated previously. ${ }^{20}$ Because of the inclusion of men as control subjects and the small number of subjects, this positive association needs support from further studies.

KCNJ11 encodes the other subunit of the $\beta$-cell ATP-sensitive potassium $\left(\mathrm{K}_{\mathrm{ATP}}\right)$ channel. A variant has been identified in the KCNJ11 gene that results in substitution of a lysine for a 
glutamic acid, Glu23Lys. In vitro studies have demonstrated that the variant induces overactivity of pancreatic $\beta$-cell $\mathrm{K}_{\mathrm{ATP}}$ channels, leading to decreased insulin secretion. ${ }^{21}$ Given the role of KCNJ11 in insulin secretion, a number of studies have investigated the KCNJ11 Glu23Lys variant in relation to T2D. Data from a meta-analysis suggest that the population-attributable risk for T2D was $6.2 \%$ for the KCNJ11 Lys23/Lys23 genotype and $10.1 \%$ for the KCNJ11 Glu23/Lys23 and Lys23/ Lys23 genotypes combined. ${ }^{22}$ Another meta-analysis combining association studies among whites showed that the Glu23Lys variant was significantly associated with T2D with Lys23/Lys 23 homozygosity being significantly more frequent in patients with T2D than in control subjects. ${ }^{23}$

Despite strong evidence of association between this variant within the KCNJ11 gene and T2D, only one published study has reported the effect of this polymorphism on GDM. Shat et al. ${ }^{24}$ found an increased frequency of the Lys 23 allele among 588 Scandinavian women with GDM compared with 1189 nondiabetic pregnant controls $(42.2 \%$ vs. $38.3 \%$, odds ratio [OR]: 1.17, 95\% confidence interval [CI]: 1.02-1.35). These results are consistent with the impaired insulin secretion associated with the KCNJ11 Glu23Lys variant. However, the association was not adjusted for potential confounders such as age and BMI.

\section{Uncoupling protein-2 (UCP2)}

Uncoupling proteins (UCP) are members of the larger family of mitochondrial anion carrier proteins. UCPs separate oxidative phosphorylation from ATP synthesis with energy dissipated as heat, referred to as the mitochondrial proton leak. The exact role of UCP2 is still unclear, but it seems to inhibit insulin secretion in pancreatic islet $\beta$-cells. ${ }^{25} \mathrm{~A}$ polymorphism in the promoter region of the UCP2 gene has been identified, $-866 \mathrm{G}>\mathrm{A} .{ }^{26}$ The $-866 \mathrm{~A}$ allele is associated with enhanced adipose tissue mRNA expression in vivo and results in increased transcription of a reporter gene in the human adipocyte cell line PAZ-6. ${ }^{26}$ Previously, the $-866 \mathrm{G}>\mathrm{A}$ polymorphism had been associated with a lower risk of obesity and a slightly lower risk of T2D. ${ }^{26,27}$

This polymorphism has only been investigated in relation to GDM in one study by Shaat et al. ${ }^{24}$ They found similar -866G allele frequency in 588 Scandinavian women with GDM and in 1189 control women $(61.8 \%$ vs. $60.2 \%$, OR: $1.07,95 \%$ CI: 0.92-1.23). Lack of statistical power is unlikely to account for absence of association, because the study had $99 \%$ power to detect an effect. Therefore, in Scandinavian women, the -866 G $>$ A polymorphism does not seem to confer increased risk of GDM.

\section{Mitochondrially encoded NADH dehydrogenase 1 (ND1)}

Mitochondrial NADH dehydrogenase, subunit 1 (ND1), is part of the electron transport chain and is involved in glucose metabolism. Reduced activity of the respiratory chain and decreased production of ATP in the mitochondria result in insulin secretion defects. ${ }^{28}$ Three studies have reported associations between variants within the mitochondrial ND1 gene and T2D. ${ }^{29-31}$

Chen et al. ${ }^{32}$ investigated the association between several nucleotide variations within the ND1 gene and GDM in a casecontrol study. The cohort included 137 Singaporean women with GDM and 292 nondiabetic pregnant women with normal glucose tolerance. Carriers of the Thr31 allele of the Met31Thr polymorphism were observed more frequently among women with GDM than among control subjects $(2.9 \%$ vs. $0 \%, P=$ $0.01)$. However, rare allele carriers for the other variants studied occurred with similar frequency in GDM and control subjects. Interestingly, $75 \%$ of women with GDM who carried the high risk allele (Thr31) had a maternal history of diabetes, suggesting a maternal influence on the development of GDM in these women. Although no functional data are available to confirm the functional effect of this variant, the substitution is in a highly conserved position of the mitochondrially encoded ND1 of several mammalian species, which suggests that the variant may have important physiological consequences for the role of this protein.

\section{Transcription factor 7-like 2 (TCF7L2)}

The transcription factor 7-like 2 (TCF7L2) is a member of the Wnt signaling pathway, but its role in the pathogenesis of diabetes is not well understood. Recent studies have shown a consistent and strong association between variants of TCF7L2 and $\mathrm{T} 2 \mathrm{D}^{33}$ potentially through a mechanism involving insulin secretion. $^{34-36}$

The association between TCF7L2 variants and GDM has been studied in two different populations. Shaat et al. ${ }^{37}$ found that the $\mathrm{T}$ allele of the rs7903146 (IVS3C > T) variant was associated with an increased risk for GDM among 1881 unrelated pregnant Scandinavian women (649 with GDM and 1232 nondiabetic controls). The effect size for GDM reported by this group was similar to that reported in patients with T2D. ${ }^{33}$ Watanabe et al. ${ }^{38}$ observed that the $\mathrm{T}$ allele of the rs 12255372 variant was more frequent among 94 Mexican-American women with previous GDM compared with 58 control subjects. These results suggest that TCF7L2 may be involved in GDM.

\section{Insulin and insulin signaling genes}

\section{Insulin (INS)}

Considering the role of insulin in the pathogenesis of diabetes, the gene INS encoding this hormone is a candidate gene for the study of T2D. A variable number of tandem repeats (VNTR) located approximately $0.5 \mathrm{~kb}$ upstream of the insulin gene has been identified and consists of a 14-15 bp unit consensus sequence (ACAGGGGTCTGGGG) with slight variations of the repeat sequence. ${ }^{39,40}$ Expression of the INS gene in the pancreas seems to be influenced by the number of repeats of this VNTR polymorphism, with the class III allele showing lower expression than the class I allele. ${ }^{41}$ The INS VNTR class III allele has been linked to a greater risk of T2D in some ${ }^{42,43}$ but not all ${ }^{44,45}$ studies, whereas the class I allele shows a protective effect for type 1 diabetes. ${ }^{42}$ 
The relationship between the INS VNTR polymorphism and GDM has been less studied. In a study by Shaat et al. ${ }^{46}$ the frequency of the INS VNTR III allele in 400 Scandinavian women with GDM was similar to that found in 428 nondiabetic women from the same population. Among women of Arabian origin, the INS VNTR III allele occurred with similar frequency in 100 diabetic pregnant women and 122 nondiabetic pregnant women. Conversely, Litou et al. ${ }^{47}$ found that the VNTR III allele frequency was higher among 161 women diagnosed with GDM compared with 111 normal glucose tolerant women, all of Greek ethnic origin. Discrepancies may be attributable to differences in genetic background.

\section{Insulin receptor (INSR)}

Because binding of insulin to the insulin receptor stimulates glucose uptake, the insulin receptor gene INSR is involved in the regulation of glucose homeostasis. Rare mutations in INSR cause syndromes displaying severe insulin resistance. ${ }^{48}$ INSR polymorphisms have been associated with $\mathrm{T} 2 \mathrm{D}$ and related phenotypes in some studies ${ }^{16,49}$ but not in others. ${ }^{50-52}$

Ober et al. ${ }^{53}$ investigated the association between GDM and the INSR KPNI polymorphism in 3 different populations. The cohort study included 26 black women with GDM and 47 control women, 24 white women with GDM and 49 control women, and 42 Hispanic women with GDM and 49 control women. The allele $1(15.5 \mathrm{kbp})$ frequency was similar in Hispanic women with GDM and Hispanic control women. However, among black women with GDM, the INSR KPNI allele contributed significantly to the risk of GDM $(P=0.001)$ after adjusting for BMI, family history of T2D, age, and oral contraceptive use; similar results were obtained in white women $(P=$ 0.007).

\section{Insulin-like growth factor 2 (IGF2)}

The IGF2 gene encodes a member of the insulin family of polypeptide growth factors. Their functions include mediation of growth hormone action, stimulation of growth of cultured cells, stimulation of the action of insulin, and involvement in development and growth. IGF2 also influences pancreatic $\beta$-cell growth and development by regulating $\beta$-cell replication, renewal, and apoptosis. ${ }^{54,55}$ The IGF2 gene is adjacent to the INS gene. Data from animal studies have demonstrated the role of IGF2 in body weight regulation and lipid metabolism. ${ }^{56,57}$ In addition, low IGF2 levels predict weight gain in subjects with T2D, ${ }^{58}$ and variants within the IGF2 gene have been associated with T2D. ${ }^{59}$

Ober et al. ${ }^{53}$ investigated whether the IGF2 BamHI polymorphism is associated with GDM in three different populations, including 28 black women with GDM and 51 control women, 24 white women with GDM and 53 control women, and 42 Hispanic women with GDM and 57 control women. The allele 1 ( $2.2 \mathrm{kbp})$ frequency in black and Hispanic women with GDM was similar to the frequency in their respective controls. Among white women, allele 1 (2.2 kbp) was more common among control subjects than in GDM patients ( $77 \%$ vs. $64 \%)$. In a multiple logistic regres- sion analysis that included body mass index (BMI), family history of GDM, gravidity, and INSR KPNI allele 1 carriage, allele 2 (1.2 kbp) of IGF2 BamHI contributed significantly to GDM when occurring in combination with the INSR KPNI allele 1 but not independently. The OR for women with BMI $=30$, INSR KPNI allele 1, and IGF2 BamHI allele 2 is 34 times greater than for women with the same BMI and INSR KPNI allele 1, but without IGF2 BamHI allele $2(\mathrm{OR}=67.76$ vs. 2.01$)$. These results should, however, be interpreted with caution because of the small number of subjects and the deviation of the genotype distribution from a Hardy-Weinberg equilibrium.

\section{Insulin receptor substrate 1 (IRS1)}

IRS1 is a substrate of the insulin receptor tyrosine kinase and a putative participant in insulin signaling. ${ }^{60}$ After phosphorylation of tyrosine by the insulin receptor kinase, IRS1 recruits and activates signal transduction molecules in the insulin signaling cascade. ${ }^{60}$ Because of the central role of the IRS1 gene in the signal transduction pathway, many studies have investigated the role of polymorphisms within this gene in the pathogenesis of T2D. ${ }^{61,62}$ In vitro studies demonstrated that the Gly972Arg polymorphism reduced tyrosine phosphorylation and allowed IRS1 to inhibit the insulin receptor kinase, producing global insulin resistance. ${ }^{61} \mathrm{~A}$ meta-analysis showed that carriers of the $972 \mathrm{Arg}$ variant of the IRS1 gene had a $25 \%$ greater risk of having T2D, compared with noncarriers. ${ }^{62}$

Considering the role of IRS1 in insulin signaling, the Gly972Arg polymorphism was investigated in association with GDM. Fallucca et al. ${ }^{63}$ observed that the frequency of the IRS1 Arg972 allele was higher in 309 white women with GDM than in 277 with normal glucose tolerance. Conversely, Shaat et al. ${ }^{24}$ observed a similar 972Arg allele frequency in 588 Scandinavian women having GDM and 1189 nondiabetic pregnant controls (4.8\% compared with 4.7\%, OR: 1.04, 95\% CI: 0.75-1.44). Similarly, Tok et al. ${ }^{64}$ found that the frequency of the heterozygote genotype (Gly972/Arg) was similar in 62 women with GDM and in 100 control women of unspecified ethnicity. Although no association between the IRS1 Gly972Arg polymorphism and GDM was observed in these two studies, other results deserve further attention. First, in the Scandinavian study, homozygosity for the Arg972 allele (Arg972/Arg972) was found exclusively in women with GDM. ${ }^{24}$ Furthermore, the variant was associated with higher fasting glucose and insulin levels in women with GDM in the study by Tok et al. ${ }^{64}$

\section{Lipid and glucose metabolism genes}

Peroxisome proliferative activated receptor, gamma (PPARG)

PPARG is a transcription factor that regulates adipocyte differentiation as well as lipid and glucose metabolism. ${ }^{65}$ PPARG binds to specific response-elements in the promoter regions of target genes and influences their expression. ${ }^{65} \mathrm{~A}$ variant in PPARG has been identified and involves the substitution of an alanine for a proline at amino acid 12 (Pro12Ala). ${ }^{66}$ Transfection assays have demonstrated that the Ala12 variant was associated with lower binding affinity of PPARG to the promoter 
element, suggesting a functional effect of this variant on the protein. ${ }^{66}$ The PPARG Pro12Ala polymorphism has been extensively studied in relation to T2D. Data from a meta-analysis suggest that the more common Pro12 allele confers a modestly increased risk of T2D; but when translated at the population level, the attributable risk in the general population is estimated at $25 \% .{ }^{67}$ The finding of decreased insulin sensitivity among carriers of the Pro12 allele supports results from this meta-analysis. ${ }^{66}$

Shaat et al. ${ }^{46}$ examined the association between the PPARG Pro12Ala polymorphism and GDM in two samples of Scandinavian and Arabian origin. Among 400 Scandinavian women with GDM, the frequency of the Ala12 allele was similar to that found in 428 nondiabetic pregnant controls (14.6\% vs. 13.7\%, $P>0.05)$. Similar results were obtained in 100 Arabian women with GDM compared with 122 Arabian controls (4.5\% vs. $7.0 \%, P>0.05)$. Because of the role of this polymorphism in T2D, an association with GDM had been expected. The authors point out that the negative findings may result from a lack of power to detect the true association, because the sample size required to demonstrate associations exceeds the sample size in this study. However, the same research group found no association in a larger study including 649 Scandinavian women with GDM and 1232 nondiabetic controls. ${ }^{37}$

\section{Peroxisome proliferative activated receptor-gamma coactivator 1-alpha (PPARGC1A)}

PPARGC1A is a coactivator of PPARG and PPARA and regulates genes involved in energy metabolism. ${ }^{68}$ The most-studied variants within this gene are the substitution of an amino acid serine for a glycine at position 482 (Gly482Ser) and the Thr394Thr variant. The functional significance of these variants has been assessed only for the Gly482Ser variant. Transient transfections of PAZ- 6 cells demonstrated that the extent of the PPAR $\gamma$-mediated transactivation of the uncoupled protein-1 promoter was similar for PPARGC1 constructs containing either the Gly 482 or the Ser482 allele. ${ }^{69}$ The lack of functional effect of this variant might explain the lack of consistency among association studies with T2D. ${ }^{70-75}$

The Gly482Ser variant was investigated in relation to GDM among 100 cases and 100 control women randomly selected from a cohort of 875 subjects, all of Caucasian origin. ${ }^{76}$ Leipold et al. ${ }^{76}$ found no significant difference in the allele distributions of the two PPARGC1A polymorphisms between women with GDM and control subjects. According to the authors, the study has sufficient power-at $90 \%$ power - to detect an effect. Similarly, no association was found among 649 Scandinavian women with GDM and 1232 nondiabetic control subjects ${ }^{37}$ suggesting that polymorphisms within the PPARGC1 gene are not likely to predispose to GDM.

\section{$\beta-3$ adrenergic receptor (ADRB3)}

The $\beta-3$ adrenergic receptor is expressed in adipose tissue and regulates energy expenditure and lipolysis in omental fat cells. ${ }^{77,78} \mathrm{~A}$ variant resulting in a replacement of a tryptophan by an arginine in codon 64 has been identified in the ADRB3 gene (Trp64Arg). ${ }^{79,80}$ The functional impact of this variant has been evaluated in several studies, but the results are inconclusive. In vitro studies have demonstrated no change in the activation of adenylate cyclase or in lipolysis, but a reduction in the amount of accumulated cAMP has been observed in some but not all studies. ${ }^{81-83}$ This variant has been associated with earlier onset of T2D in different populations, including Pima Indians, Finns, and Japanese. ${ }^{84}$ Moreover, in a study by Fujisawa et al., ${ }^{85}$ the Arg64/Arg64 genotype was moderately associated with a higher risk of T2D when data from Finns, Pima Indians, and Japanese subjects were combined (relative risk: 2.13, 95\% CI: $1.28-3.55)$.

Studies of the association between GDM and this variant within $A D R B 3$ have yielded conflicting results. Festa et al. were the first to report an association between the ADRB3 Trp64Arg polymorphism and GDM. ${ }^{86}$ Among 179 white women recruited, 70 were diagnosed as having GDM. The Trp64Arg genotype (Trp64/Arg64 heterozygote) was more frequent in women with GDM than in those with normal glucose tolerance ( $26 \%$ vs. $11 \%, P=0.01$ ). Moreover, the Trp64/Arg64 genotype was a significant predictor of GDM (OR: 5.92, 95\% CI: 1.54-24.1) when the association was adjusted for age, BMI, and gestational age. However, this positive association was not confirmed in subsequent studies involving women of Greek, Taiwanese, and Scandinavian origins. Indeed, Alevizaki et al. ${ }^{87}$ found a similar Arg64 allele frequency in 180 Greek women with GDM and 131 women without this condition ( 0.033 vs. $0.034, P=\mathrm{NS}$ ). Among 649 Scandinavian women with GDM and 1232 nondiabetic controls, the Arg64 allele was not associated with GDM. ${ }^{37}$ The Arg64 allele frequency was also comparable between 309 white women with GDM and 277 women with normal glucose tolerance. ${ }^{63}$ Similar findings were obtained by Tsai et al. ${ }^{88}$ in a cohort of 299 Taiwanese women: 258 with normal glucose tolerance and 41 with GDM. Although Arg64 carriers with GDM had higher fasting and 120-minute postload insulin levels than did homozygotes for the wild-type allele, the Arg64 allele frequency was similar in the control and the GDM groups $(0.145$ vs. $0.098, P=0.086) .{ }^{88}$ In addition to differences in study populations, diagnostic criteria for GDM differed among studies, with more stringent criteria used in the studies of Tsai et al. ${ }^{88}$ and Alevizaki et al., ${ }^{87}$ which could explain the divergent results.

\section{Glucose transporter 1 (GLUT1)}

Glucose transporters are involved in the transport of glucose in most cells. GLUT1 (solute carrier family 2 [facilitated glucose transporter], member 1) is a functional isoform of the GLUT family. GLUT1, the first isoform cloned, ${ }^{89}$ is expressed in high density in the membranes of human erythrocytes and is characteristically expressed in blood-tissue barriers, the bloodocular barriers, and the blood-placental and blood-testis barriers. ${ }^{90} \mathrm{~A}$ polymorphism at the Xba I restriction site has been associated with T2D in some ${ }^{91-94}$ but not all ${ }^{95-97}$ studies.

Ober et al..$^{53}$ investigated in three different populations whether the Xba I polymorphism (resulting in two fragments of 6.3 and $6.0 \mathrm{~kb}$ ) is associated with GDM. The cohort study 
included 28 black women with GDM and 51 control women. A sample of 24 white women with GDM and 53 glucose-tolerant women was also studied, as well as 42 Hispanic women with GDM and 57 control subjects. In all three populations, the allele frequency was similar in women with GDM and control women. Because the low number of subjects could result in lack of power to detect a small effect, it is difficult to draw a conclusion from this one study. However, these results suggest little or no impact of this GLUT1 Xba I variant on the risk for GDM.

\section{Adiponectin (ADIPOQ)}

Adiponectin is a hormone secreted by adipocytes that regulates energy homeostasis and glucose and lipid metabolism. Several studies have demonstrated the association of T2D with genetic variants within ADIPOQ. ${ }^{98-106}$ In one French cohort, several single nucleotide polymorphisms (SNPs) within ADI$P O Q$ were found to be moderately associated with T2D (OR range: $1.31-2.69) .{ }^{105}$ Similarly, in a Japanese population, the presence of the deleterious genotype found to be was associated with an increased risk of T2D (OR: 2.16, 95\% CI: $1.22-$ 3.95). ${ }^{100}$ Interestingly, women with impaired glucose tolerance, at high risk for $\mathrm{T} 2 \mathrm{D}$, and carrying two risk alleles within $A D I P O Q$, had a higher conversion rate to diabetes than did women with none of these alleles (OR: 4.49, 95\% CI: $1.78-11.3) .{ }^{106}$

Because of its association with T2D and the fact that women with GDM present hypoadiponectinemia, ${ }^{107-118}$ ADIPOQ represents a promising candidate gene for GDM. To our knowledge, only one study has examined the association between $A D I P O Q$ variants and GDM. They found that the frequency of the $\mathrm{T}$ allele of the rs1501299 variant $(+276 \mathrm{G}>\mathrm{T})$ was similar between 649 Scandinavian women with GDM and 1232 nondiabetic control subjects. ${ }^{37}$

\section{Forkhead box C2 (FOXC2)}

Human Forkhead-box (FOX) gene family consists of at least 43 members, including the Forkhead box C2 (FOXC2). ${ }^{119}$ FOXC2 regulates several aspects of adipocyte metabolism and in animal models FOXC2 has been shown to be a major regulator of glucose metabolism, including protection against dietinduced insulin resistance. ${ }^{120}$ However, results from association studies between FOXC2 variants and T2D or T2D-related traits have been inconclusive. ${ }^{121-125}$

The association between GDM and FOXC2 variants has been examined in one study including 649 Scandinavian women with GDM and 1232 nondiabetic controls. ${ }^{37}$ They found that the $-512 \mathrm{C}$ allele frequency of the FOXC2 $-512 \mathrm{C}>\mathrm{T}$ variant was not associated with GDM. ${ }^{37}$

\section{Maturity-onset diabetes of the young (MODY) genes}

MODY is a monogenic form of T2D and is characterized by an autosomal dominant mode of inheritance. MODY usually develops during the second or third decade of life and presents defects in insulin secretion. ${ }^{126}$ Six MODY genes have been identified: GCK (MODY2), HNF4A (MODY1), HNF1A
(MODY3), IPF1 (MODY4), HNF1B (MODY5), and NEUROD1 (MODY6).127 A growing body of scientific evidence suggests that these genes might also contribute to the development of the more common and multifactorial form of T2D. ${ }^{128}$ However, common variants within MODY genes confer only a moderate risk of T2D. ${ }^{128}$

Mutations within these genes (MODY1-MODY6) have been investigated in relation to gestational diabetes because women with MODY often develop gestational diabetes. In 648 Scandinavian women with gestational diabetes, the rare allele frequency of three variants within the HNF4A gene was similar to that of 1232 control women. ${ }^{129}$ The $G C K-30 \mathrm{G}>\mathrm{A}$ was also investigated in relation to gestational diabetes. Allan et al. ${ }^{130}$ observed that the frequency of $-30 \mathrm{~A}$ carriers in 50 women with gestational diabetes was similar to that in a control group consisting of 16 men and 39 women (35\% compared with $29 \%$, $P=0.26$ ). The sample included individuals of Caucasian, Oriental, and black origin, and could have led to biased results. In Scandinavian women, Shaat et al. ${ }^{129}$ observed that the $-30 \mathrm{~A}$ allele frequency was increased among 648 women with gestational diabetes compared with 1232 control women (18.1\% vs. 14.8\%, OR: 1.28, 95\% CI: 1.06-1.53). However, in 94 American black women with gestational diabetes and 99 glucosetolerant women, the $-30 \mathrm{~A}$ allele frequency was similar $(23.2 \%$ vs. $19.2 \%$, OR: $1.37,95 \%$ CI: $0.77-2.46) .{ }^{131}$ Finally, two variants within the HNF1A gene were investigated in association with gestational diabetes. The HNF1A Ala98Val polymorphism was not associated with gestational diabetes in a casecontrol study of 376 women with gestational diabetes and 1034 control subjects, ${ }^{132}$ whereas the Leu27 allele of the Ile27Leu polymorphism was more common among a sample of 648 women with gestational diabetes compared with a sample of 1232 control women, but this result was of borderline significance $(36.3 \%$ vs. $33.0 \%$, OR:1.16, 95\% CI: $1.001-1.34)$ and was not statistically significant after correction for multiple comparisons $(P=0.17) .{ }^{129}$ Several variants within HNF1A were compared between 119 white women with GDM and 120 pregnant nondiabetic controls, and no association was observed. ${ }^{133}$ According to these results, variants within MODY genes do not confer an increased risk of gestational diabetes; however, data are limited.

\section{Other genes}

\section{Mannose-binding lectin (protein C) 2 (MBL2)}

MBL2, a member of the collectin family of proteins, is considered an important component of the innate immune system. ${ }^{134}$ Additionally, MBL2 influences inflammatory response by inhibiting TNF- $\alpha$ release, ${ }^{135}$ and its deficiency predisposes individuals to recurrent infections and chronic inflammatory diseases. ${ }^{136}$ Two variants within the MBL2 gene are associated with decreased plasma MBL2 levels: Arg52Cys and Gly54Asp. ${ }^{137-139}$ These polymorphisms, particularly Gly54Asp, are common in the European population ${ }^{138}$ and have been previously linked to micro- and macrovascular complications associated with type 1 diabetes. ${ }^{140}$ Surprisingly, given the role of MBL2 in inflam- 
matory response, we found no studies that assessed the role of these polymorphisms in T2D.

Megia et al. ${ }^{141}$ investigated the association between MBL2 Gly54Asp and Arg52Cys and GDM in a case-control study of 105 women with GDM and 173 control women matched for geographic origin. The Arg52Cys polymorphism was not associated with GDM; the frequency of heterozygotes for this polymorphism was similar in patients and controls $(8.6 \%$ compared with $11.6 \%, P=\mathrm{NS}$ ). However, carriers of the Asp54 allele of the Gly54Asp polymorphism were at increased risk for GDM compared with control subjects (carriers of the Asp54 allele: $43.8 \%$ compared with $27.9 \%$, OR: 2.03, 95\% CI: $1.18-3.49$ ).

\section{Calpain 10 (CAPN10)}

Calpains are processing proteases that cleave specific substrates at a limited number of sites, and cause activation or inactivation of protein function. ${ }^{142}$ They have been implicated in the regulation of a variety of cellular functions, including intracellular signaling, proliferation, and differentiation, and may be responsible for adipocyte differentiation ${ }^{143}$ as well as insulininduced down-regulation of insulin receptor substrate-1. ${ }^{144}$ Several SNPs have been identified within the CAPN10 gene. Among them, the SNP-43 regulates calpain-10 expression. ${ }^{145}$ This SNP, as well as the SNP-19 and SNP-63 in allelic combination, have been previously associated with an increased risk for T2D. ${ }^{145}$ This finding has been confirmed in a meta-analysis by Weedon et al. ${ }^{146}$

In light of the potential physiological link between T2D and GDM, two studies investigated the relationship between variants within the CAPN10 gene and GDM. Shaat et al. ${ }^{24}$ first observed that the minor allele frequency of both SNPs (SNP-43 and SNP-44) was similar in a sample of 588 Scandinavian women with GDM and in 1189 control subjects (SNP-43: $71.9 \%$ vs. $72.6 \%$, OR: $0.96,95 \%$ CI: $0.82-1.13$ and SNP-44: $18 \%$ vs. $18.5 \%$, OR: $0.97,95 \%$ CI: $0.81-1.16)$. Similarly, Leipold et al. ${ }^{147}$ found no difference in the allele frequencies for SNP-43, -19 , and -63 between 40 white women with GDM living in Vienna and 40 control subjects randomly selected from an 875 subject cohort. However, there was a higher frequency of women homozygous for allele 1 of SNP-63 among gestational diabetics compared with controls (59\% vs. $41 \%$, $P=0.02$ ). Furthermore, haplotype analyses revealed that all women with the haplotype combination 121/221 $(n=8)$ had GDM, suggesting a moderate impact of these variants on the risk of GDM. Considering the association of T2D with CAPN10 variants, and the common etiologic pathways between T2D and GDM, further studies involving large cohorts are needed to understand the role of CAPN1O variants in GDM.

\section{Plasminogen activator inhibitor type 1 (PAI-1)}

PAI-1 (or serpin peptidase inhibitor, clade E, member 1) regulates the antifibrinolytic activity of the plasma. ${ }^{148}$ Other functions of PAI-1 described in the literature include tumorigenesis, angiogenesis, wound healing, ovulation, and embryo- genesis, although its exact role remains unclear. ${ }^{149}$ Adipose tissue produces large amounts of PAI-1, which suggests a possible role of PAI-1 in the control of body fat mass. ${ }^{149}$ Moreover, elevated plasma PAI-1 levels have been associated with obesity, insulin resistance, and T2D. ${ }^{150,151}$ Polymorphisms have been described that influence PAI-1 gene expression, and therefore PAI-1 activity. Among these, the lowest PAI- 1 activity has been observed among 5G/5G homozygotes for the $-6754 \mathrm{G} / 5 \mathrm{G}$ variant. ${ }^{152}$ This variant has been associated with decreased risk of obesity and cardiovascular disease. ${ }^{152-154}$

Leipold et al. ${ }^{155}$ examined whether this polymorphism is associated with GDM in a cohort of 40 white women with and 40 without GDM. They found that the genotype distribution was significantly different between women with GDM and normal glucose-tolerant women. The 5G/5G genotype was much less common among women with GDM than in control subjects ( $5 \%$ vs. $25 \%, P=0.01$ ). Furthermore, in a multiple logistic regression analysis, the $P A I-1$ genotype was a significant predictor of GDM, independent of maternal age and BMI (OR: 0.16, 95\% CI: 0.03-0.87). Although this study was performed on a small sample, these results are the first to suggest a possible association between the PAI-1 - 675 4G/5G polymorphism and GDM.

\section{DISCUSSION}

This review has focused on genes investigated in association with GDM, and highlights the growing body of scientific evidence suggesting the role of genetic factors in the pathogenesis of GDM. Also, importantly, it has identified the need for further studies in this field. To date, most of the genetic association studies of GDM have been performed in white populations and few have reported associations in high-risk populations such as American Indians and Mexican Americans. Although several genes (GLUT1, TCF7L2, PPARGC1, and $P P A R G$ ) have produced similar findings when studied in different populations, most genes have been investigated only in a single study or a single population, accentuating the need for additional studies. Disparities among findings have also been observed. For instance, associations between GDM and IGF2, INS, IRS1, ADRB3, and INSR have led to different findings across populations. Several factors may account for inconsistent findings among studies. These factors include differences in genetic background, differences in environment and lifestyle factors between populations, differences in the selection criteria for subjects in each study, and the use of samples too small to permit detection of small differences between cases and controls.

According to this review, there is no evidence to support an association between GDM and polymorphisms in several genes (GLUT1, FOXC2, IRS1, PPARGC1, and UCP2 genes) although their functions suggest a physiological influence on this condition. However, we must interpret these findings with caution considering that few studies have been performed, some including small numbers of subjects or testing only a small number of variants. For example, investigators failed to 
observe an association of PPARG with GDM. ${ }^{46}$ However, $P P A R G$ may still be a candidate gene for GDM because of its well-demonstrated association with $\mathrm{T} 2 \mathrm{D}$ and its role in glucose and lipid metabolism. ${ }^{67}$

Most genetic variants associated with GDM and reviewed in the present report have also been involved in the development of T2D. These represent the most interesting genetic markers for identifying women with a history of GDM who are at risk for subsequent development of T2D. At present, based on the literature review and on previous association with T2D, as well as on their physiological role in the pathogenesis of diabetes, variants within CAPN10, MBL2, KCNJ11, ABCC8, ND1, TCF7L2, ADIPOQ, and PAI-1 genes are considered the most promising markers. However, it is important to take into account that these results are based on few studies with small sample size. Replication of these findings will be needed in different populations.

This review highlighted the fact that the study of the genetics of GDM is in its early stage. Findings from these studies combined with evidence of a common physiopathology between GDM and T2D support the idea that it is unlikely that GDM has a unique genetic predisposition but rather is a manifestation of multiple susceptibility variants for T2D. Identification of genetic variants linked to GDM will contribute to our understanding of the physiopathology of GDM and to the development of prevention strategies. Moreover, the recognition of individuals with a genetic predisposition may improve prevention of T2D through targeted intervention. To achieve such goals, further studies are needed to more fully understand the genetic components of GDM that lead to an increased risk of T2D. The success of whole genome association studies in identifying susceptibility genes for T2D should benefit the study of genetics of GDM. This success will be achieved if large case-control samples are recruited through collaborative studies and if the study of different populations particularly those at high risk for T2D such as Mexican Americans and the careful selection of cases based on similar diagnosis criteria are considered.

\section{ACKNOWLEDGMENTS}

This work was supported, in part, by the Fellowship in Genetics and Public Health Research and Practice Program (to J.R.) jointly sponsored by the Centers for Disease Control and Prevention and the American Society of Human Genetics. J.R. is also the recipient of a fellowship award from the Canadian Institutes of Health Research.

\section{References}

1. American Diabetes Association. Gestational diabetes 2006 [internet communication]. 2006

2. Phillips PJ, Jeffries B. Gestational diabetes-worth finding and actively treating. Aust Fam Physician 2006;35:701-703.

3. Lobner K, Knopff A, Baumgarten A, Mollenhauer U, et al. Predictors of postpartum diabetes in women with gestational diabetes mellitus. Diabetes 2006;55:792-797.

4. Silverman BL, Rizzo TA, Cho NH, Metzger BE. Long-term effects of the intrauterine environment. The Northwestern university diabetes in pregnancy center. Diabetes Care 1998;21(suppl 2):B142-B149.

5. Permutt MA, Wasson J, Cox N. Genetic epidemiology of diabetes. J Clin Invest 2005;115:1431-1439.
6. Buchanan TA, Xiang AH. Gestational diabetes mellitus. J Clin Invest 2005;115:485491.

7. Buchanan TA. Pancreatic B-cell defects in gestational diabetes: implications for the pathogenesis and prevention of type 2 diabetes. J Clin Endocrinol Metab 2001;86: 989-993.

8. Williams MA, Qiu C, Dempsey JC, Luthy DA. Familial aggregation of type 2 diabetes and chronic hypertension in women with gestational diabetes mellitus. J Reprod Med 2003;48:955-962.

9. Martin AO, Simpson JL, Ober C, Freinkel N. Frequency of diabetes mellitus in mothers of probands with gestational diabetes: possible maternal influence on the predisposition to gestational diabetes. Am J Obstet Gynecol 1985;151:471-475.

10. Harder T, Franke K, Kohlhoff R, Plagemann A. Maternal and paternal family history of diabetes in women with gestational diabetes or insulin-dependent diabetes mellitus type I. Gynecol Obstet Invest 2001;51:160-164.

11. Barroso I. Genetics of Type 2 diabetes. Diabet Med 2005;22:517-535.

12. Froguel P, Velho G. Genetic determinants of type 2 diabetes. Recent Prog Horm Res 2001;56:91-105.

13. Malecki MT. Genetics of type 2 diabetes mellitus. Diabetes Res Clin Pract 2005; 68(suppl 1):S10-S21.

14. Shaat N, Groop L. Genetics of gestational diabetes mellitus. Curr Med Chem 2007; 14:569-583.

15. Gloyn AL, Siddiqui J, Ellard S. Mutations in the genes encoding the pancreatic beta-cell KATP channel subunits Kir6.2 (KCNJ11) and SUR1 (ABCC8) in diabetes mellitus and hyperinsulinism. Hum Mutat 2006;27:220-231.

16. Hart LM, Stolk RP, Dekker JM, Nijpels G, et al. Prevalence of variants in candidate genes for type 2 diabetes mellitus in The Netherlands: the Rotterdam study and the Hoorn study. J Clin Endocrinol Metab 1999;84:1002-1006.

17. Hart LM, Dekker JM, van Haeften TW, Ruige JB, et al. Reduced second phase insulin secretion in carriers of a sulphonylurea receptor gene variant associating with Type II diabetes mellitus. Diabetologia 2000;43:515-519.

18. Inoue H, Ferrer J, Welling CM, Elbein SC, et al. Sequence variants in the sulfonylurea receptor (SUR) gene are associated with NIDDM in Caucasians. Diabetes 1996;45:825-831.

19. Rissanen J, Markkanen A, Karkkainen P, Pihlajamaki J, et al. Sulfonylurea receptor 1 gene variants are associated with gestational diabetes and type 2 diabetes but not with altered secretion of insulin. Diabetes Care 2000;23:70-73.

20. Goksel DL, Fischbach K, Duggirala R, Mitchell BD, et al. Variant in sulfonylurea receptor-1 gene is associated with high insulin concentrations in non-diabetic Mexican Americans: SUR-1 gene variant and hyperinsulinemia. Hum Genet 1998; 103:280-285.

21. Schwanstecher C, Meyer U, Schwanstecher M. K(IR)6.2 polymorphism predisposes to type 2 diabetes by inducing overactivity of pancreatic beta-cell ATP-sensitive $\mathrm{K}(+)$ channels. Diabetes 2002;51:875-879.

22. van Dam RM, Hoebee B, Seidell JC, Schaap MM, et al. Common variants in the ATP-sensitive $\mathrm{K}+$ channel genes KCNJ11 (Kir6.2) and ABCC8 (SUR1) in relation to glucose intolerance: population-based studies and meta-analyses. Diabet $\mathrm{Med}$ 2005;22:590-598.

23. Hani EH, Boutin P, Durand E, Inoue H, et al. Missense mutations in the pancreatic islet beta cell inwardly rectifying $\mathrm{K}+$ channel gene (KIR6.2/BIR): a meta-analysis suggests a role in the polygenic basis of Type II diabetes mellitus in Caucasians. Diabetologia 1998;41:1511-1515.

24. Shaat N, Ekelund M, Lernmark A, Ivarsson S, et al. Association of the E23K polymorphism in the KCNJ11 gene with gestational diabetes mellitus. Diabetologia 2005;48:2544-2551.

25. Zhang CY, Baffy G, Perret P, Krauss S, et al. Uncoupling protein-2 negatively regulates insulin secretion and is a major link between obesity, beta cell dysfunction, and type 2 diabetes. Cell 2001;105:745-755.

26. Esterbauer H, Schneitler C, Oberkofler H, Ebenbichler C, et al. A common polymorphism in the promoter of UCP2 is associated with decreased risk of obesity in middle-aged humans. Nat Genet 2001;28:178-183.

27. Wang H, Chu WS, Lu T, Hasstedt SJ, et al. Uncoupling protein-2 polymorphisms in type 2 diabetes, obesity, and insulin secretion. Am J Physiol Endocrinol Metab 2004;286:E1-E7.

28. Maassen JA, Jahangir Tafrechi RS, Janssen GM, Raap AK, et al. New insights in the molecular pathogenesis of the maternally inherited diabetes and deafness syndrome. Endocrinol Metab Clin North Am 2006;35:385-396, x-xi.

29. Guo LJ, Oshida Y, Fuku N, Takeyasu T, et al. Mitochondrial genome polymorphisms associated with type-2 diabetes or obesity. Mitochondrion 2005;5:15-33.

30. Tang DL, Zhou X, Li X, Zhao L, et al. Variation of mitochondrial gene and the association with type 2 diabetes mellitus in a Chinese population. Diabetes Res Clin Pract 2006;73:77-82.

31. Yu P, Yu DM, Liu DM, Wang K, et al. Relationship between mutations of mitochondrial DNA ND1 gene and type 2 diabetes. Chin Med J (Engl) 2004;117:985989. 
32. Chen Y, Liao WX, Roy AC, Loganath A, et al. Mitochondrial gene mutations in gestational diabetes mellitus. Diabetes Res Clin Pract 2000;48:29-35.

33. Grant SF, Thorleifsson G, Reynisdottir I, Benediktsson R, et al. Variant of transcription factor 7-like 2 (TCF7L2) gene confers risk of type 2 diabetes. Nat Genet 2006;38:320-323.

34. Palmer ND, Lehtinen AB, Langefeld CD, Campbell JK, et al. Association of TCF7L2 gene polymorphisms with reduced acute insulin response in Hispanic Americans. J Clin Endocrinol Metab 2008;93:304-309

35. Loos RJ, Franks PW, Francis RW, Barroso I, et al. TCF7L2 polymorphisms modulate proinsulin levels and beta-cell function in a British Europid population. $\mathrm{Di}$ abetes 2007;56:1943-1947.

36. Munoz J, Lok KH, Gower BA, Fernandez JR, et al. Polymorphism in the transcription factor 7-like 2 (TCF7L2) gene is associated with reduced insulin secretion in nondiabetic women. Diabetes 2006;55:3630-3634.

37. Shaat N, Lernmark A, Karlsson E, Ivarsson S, et al. A variant in the transcription factor 7-like 2 (TCF7L2) gene is associated with an increased risk of gestational diabetes mellitus. Diabetologia 2007;50:972-979.

38. Watanabe RM, Allayee H, Xiang AH, Trigo E, et al. Transcription factor 7-like 2 (TCF7L2) is associated with gestational diabetes mellitus and interacts with adiposity to alter insulin secretion in Mexican Americans. Diabetes 2007;56:14811485 .

39. Bell GI, Selby MJ, Rutter WJ. The highly polymorphic region near the human insulin gene is composed of simple tandemly repeating sequences. Nature 1982; 295:31-35.

40. Kennedy GC, German MS, Rutter WJ. The minisatellite in the diabetes susceptibility locus IDDM2 regulates insulin transcription. Nat Genet 1995;9:293-298.

41. Lucassen AM, Screaton GR, Julier C, Elliott TJ, et al. Regulation of insulin gene expression by the IDDM associated, insulin locus haplotype. Hum Mol Genet 1995; 4:501-506.

42. Bennett ST, Todd JA. Human type 1 diabetes and the insulin gene: principles of mapping polygenes. Annu Rev Genet 1996;30:343-370.

43. Meigs JB, Dupuis J, Herbert AG, Liu C, et al. The insulin gene variable number tandem repeat and risk of type 2 diabetes in a population-based sample of families and unrelated men and women. J Clin Endocrinol Metab 2005;90:1137-1143.

44. Hansen SK, Gjesing AP, Rasmussen SK, Glumer C, et al. Large-scale studies of the $\mathrm{HphI}$ insulin gene variable-number-of-tandem-repeats polymorphism in relation to Type 2 diabetes mellitus and insulin release. Diabetologia 2004;47:1079-1087.

45. Lindsay RS, Hanson RL, Wiedrich C, Knowler WC, et al. The insulin gene variable number tandem repeat class I/III polymorphism is in linkage disequilibrium with birth weight but not Type 2 diabetes in the Pima population. Diabetes 2003;52:187193.

46. Shaat N, Ekelund M, Lernmark A, Ivarsson S, et al. Genotypic and phenotypic differences between Arabian and Scandinavian women with gestational diabetes mellitus. Diabetologia 2004;47:878-884.

47. Litou H, Anastasiou E, Thalassinou L, Sarika HL, et al. Increased prevalence of VNTR III of the insulin gene in women with gestational diabetes mellitus (GDM). Diabetes Res Clin Pract 2007;76:223-228.

48. Taylor SI, Accili D, Cama A, Imano E, et al. Unusual forms of insulin resistance. Annu Rev Med 1991;42:373-379.

49. Morgan R, Bishop A, Owens DR, Luzio SD, et al. Allelic variants at insulin-receptor and insulin gene loci and susceptibility to NIDDM in Welsh population. Diabetes 1990;39:1479-1484.

50. Flores-Martinez SE, Islas-Andrade S, Horro-Lazo MV, Revilla MC, et al. DNA polymorphism analysis of candidate genes for type 2 diabetes mellitus in a Mexican ethnic group. Ann Genet 2004;47:339-348.

51. Lepretre F, Vionnet N, Budhan S, Dina C, et al. Genetic studies of polymorphisms in ten non-insulin-dependent diabetes mellitus candidate genes in Tamil Indians from Pondicherry. Diabetes Metab 1998;24:244-250.

52. Magre J, Goldfine AB, Warram JH, Krolewski AS, et al. Analysis of the insulin receptor gene in noninsulin-dependent diabetes mellitus by denaturing gradient gel blots: a clinical research center study. J Clin Endocrinol Metab 1995;80:18821887.

53. Ober C, Xiang KS, Thisted RA, Indovina KA, et al. Increased risk for gestational diabetes mellitus associated with insulin receptor and insulin-like growth factor II restriction fragment length polymorphisms. Genet Epidemiol 1989;6:559-569.

54. Bonner-Weir S. Life and death of the pancreatic beta cells. Trends Endocrinol Metab 2000;11:375-378.

55. Kido Y, Nakae J, Hribal ML, Xuan S, et al. Effects of mutations in the insulin-like growth factor signaling system on embryonic pancreas development and beta-cell compensation to insulin resistance. J Biol Chem 2002;277:36740-36747.

56. Da Costa TH, Williamson DH, Ward A, Bates P, et al. High plasma insulin-like growth factor-II and low lipid content in transgenic mice: measurements of lipid metabolism. J Endocrinol 1994;143:433-439.

57. Rogler CE, Yang D, Rossetti L, Donohoe J, et al. Altered body composition and increased frequency of diverse malignancies in insulin-like growth factor-II transgenic mice. J Biol Chem 1994;269:13779-13784.

58. Heald AH, Karvestedt L, Anderson SG, McLaughlin J, et al. Low insulin-like growth factor-II levels predict weight gain in normal weight subjects with type 2 diabetes. Am J Med 2006;119:167-115.

59. Villuendas G, Botella-Carretero JI, Lopez-Bermejo A, Gubern C, et al. The ACAAinsertion/deletion polymorphism at the $3^{\prime}$ UTR of the IGF-II receptor gene is associated with type 2 diabetes and surrogate markers of insulin resistance. Eur J Endocrinol 2006;155:331-336.

60. Sun XJ, Rothenberg P, Kahn CR, Backer JM, et al. Structure of the insulin receptor substrate IRS-1 defines a unique signal transduction protein. Nature 1991;352:73-77.

61. McGettrick AJ, Feener EP, Kahn CR. Human insulin receptor substrate-1 (IRS-1) polymorphism G972R causes IRS-1 to associate with the insulin receptor and inhibit receptor autophosphorylation. J Biol Chem 2005;280:6441-6446.

62. Jellema A, Zeegers MP, Feskens EJ, Dagnelie PC, et al. Gly972Arg variant in the insulin receptor substrate- 1 gene and association with Type 2 diabetes: a metaanalysis of 27 studies. Diabetologia 2003;46:990-995.

63. Fallucca F, Dalfra MG, Sciullo E, Masin M, et al. Polymorphisms of insulin receptor substrate 1 and beta3-adrenergic receptor genes in gestational diabetes and normal pregnancy. Metabolism 2006;55:1451-1456.

64. Tok EC, Ertunc D, Bilgin O, Erdal EM, et al. Association of insulin receptor substrate-1 G972R variant with baseline characteristics of the patients with gestational diabetes mellitus. Am J Obstet Gynecol 2006;194:868-872.

65. Berger J, Moller DE. The mechanisms of action of PPARs. Annu Rev Med 2002;53: 409-435.

66. Deeb SS, Fajas L, Nemoto M, Pihlajamaki J, et al. A Prol2Ala substitution in PPARgamma2 associated with decreased receptor activity, lower body mass index and improved insulin sensitivity. Nat Genet 1998;20:284-287.

67. Altshuler D, Hirschhorn JN, Klannemark M, Lindgren CM, et al. The common PPARgamma Pro12Ala polymorphism is associated with decreased risk of type 2 diabetes. Nat Genet 2000;26:76-80.

68. Finck BN, Kelly DP. PGC-1 coactivators: inducible regulators of energy metabolism in health and disease. J Clin Invest 2006;116:615-622.

69. Esterbauer H, Oberkofler H, Linnemayr V, Iglseder B, et al. Peroxisome proliferator-activated receptor-gamma coactivator-1 gene locus: associations with obesity indices in middle-aged women. Diabetes 2002;51:1281-1286.

70. Andrulionyte L, Zacharova J, Chiasson JL, Laakso M. Common polymorphisms of the PPAR-gamma2 (Pro12Ala) and PGC-1alpha (Gly482Ser) genes are associated with the conversion from impaired glucose tolerance to type 2 diabetes in the STOP-NIDDM trial. Diabetologia 2004;47:2176-2184.

71. Chen S, Yan W, Huang J, Yang W, et al. Peroxisome proliferator-activated receptor-gamma coactivator-lalpha polymorphism is not associated with essential hypertension and type 2 diabetes mellitus in Chinese population. Hypertens Res 2004; 27:813-820.

72. Ek J, Andersen G, Urhammer SA, Gaede PH, et al. Mutation analysis of peroxisome proliferator-activated receptor-gamma coactivator-1 (PGC-1) and relationships of identified amino acid polymorphisms to Type II diabetes mellitus. Diabetologia 2001;44:2220-2226

73. Hara K, Tobe K, Okada T, Kadowaki H, et al. A genetic variation in the PGC-1 gene could confer insulin resistance and susceptibility to Type II diabetes. Diabetologia 2002;45:740-743.

74. Lacquemant C, Chikri M, Boutin P, Samson C, et al. No association between the G482S polymorphism of the proliferator-activated receptor-gamma coactivator-1 (PGC-1) gene and Type II diabetes in French Caucasians. Diabetologia 2002;45: 602-603.

75. Vimaleswaran KS, Radha V, Ghosh S, Majumder PP, et al. Peroxisome proliferator-activated receptor-gamma co-activator-1alpha (PGC-1alpha) gene polymorphisms and their relationship to Type 2 diabetes in Asian Indians. Diabet Med 2005;22:1516-1521.

76. Leipold H, Knoefler M, Gruber C, Huber A, et al. Peroxisome proliferator-activated receptor gamma coactivator-lalpha gene variations are not associated with gestational diabetes mellitus. J Soc Gynecol Investig 2006;13:104-107.

77. Krief S, Lonnqvist F, Raimbault S, Baude B, et al. Tissue distribution of beta 3-adrenergic receptor mRNA in man. J Clin Invest 1993;91:344-349.

78. Lonnqvist F, Thome A, Nilsell K, Hoffstedt J, et al. A pathogenic role of visceral fa beta 3-adrenoceptors in obesity. J Clin Invest 1995;95:1109-1116.

79. Clement K, Vaisse C, Manning BS, Basdevant A, et al. Genetic variation in the beta 3 -adrenergic receptor and an increased capacity to gain weight in patients with morbid obesity. N Engl J Med 1995;333:352-354.

80. Walston J, Silver K, Bogardus C, Knowler WC, et al. Time of onset of non-insulin dependent diabetes mellitus and genetic variation in the beta 3-adrenergic-receptor gene. N Engl J Med 1995;333:343-347.

81. Candelore MR, Deng L, Tota LM, Kelly LJ, et al. Pharmacological characterization 
of a recently described human beta 3-adrenergic receptor mutant. Endocrinology 1996;137:2638-2641.

82. Pietri-Rouxel F, St John MB, Gros J, Strosberg AD. The biochemical effect of the naturally occurring Trp64->Arg mutation on human beta3-adrenoceptor activity. Eur J Biochem 1997;247:1174-1179.

83. Weng J, Ekelund M, Lehto M, Li H, et al. Screening for MODY mutations, GAD antibodies, and type 1 diabetes-associated HLA genotypes in women with gestational diabetes mellitus. Diabetes Care 2002;25:68-71.

84. Strosberg AD. Association of beta 3-adrenoceptor polymorphism with obesity and diabetes: current status. Trends Pharmacol Sci 1997;18:449-454.

85. Fujisawa T, Ikegami H, Yamato E, Takekawa K, et al. Association of Trp64Arg mutation of the beta3-adrenergic-receptor with NIDDM and body weight gain. Diabetologia 1996;39:349-352.

86. Festa A, Krugluger W, Shnawa N, Hopmeier P, et al. Trp64Arg polymorphism of the beta3-adrenergic receptor gene in pregnancy: association with mild gestational diabetes mellitus. J Clin Endocrinol Metab 1999;84:1695-1699.

87. Alevizaki M, Thalassinou L, Grigorakis SI, Philippou G, et al. Study of the Trp64Arg polymorphism of the beta3-adrenergic receptor in Greek women with gestational diabetes. Diabetes Care 2000;23:1079-1083.

88. Tsai PJ, Ho SC, Tsai LP, Lee YH, et al. Lack of relationship between beta3-adrenergic receptor gene polymorphism and gestational diabetes mellitus in a Taiwanese population. Metabolism 2004;53:1136-1139.

89. Mueckler M, Caruso C, Baldwin SA, Panico M, et al. Sequence and structure of a human glucose transporter. Science 1985;229:941-945.

90. Kumagai AK. Glucose transport in brain and retina: implications in the management and complications of diabetes. Diabetes Metab Res Rev 1999;15:261-273.

91. Li SR, Baroni MG, Oelbaum RS, Stock J, et al. Association of genetic variant of the glucose transporter with non-insulin-dependent diabetes mellitus. Lancet 1988;2: $368-370$.

92. Baroni MG, Oelbaum RS, Pozzilli P, Stocks J, et al. Polymorphisms at the GLUT1 (HepG2) and GLUT4 (muscle/adipocyte) glucose transporter genes and non-insulin-dependent diabetes mellitus (NIDDM). Hum Genet 1992;88:557-561.

93. Tao T, Tanizawa Y, Matsutani A, Matsubara A, et al. HepG2/erythrocyte glucose transporter (GLUT1) gene in NIDDM: a population association study and molecular scanning in Japanese subjects. Diabetologia 1995;38:942-947.

94. Pontiroli AE, Capra F, Veglia F, Ferrari M, et al. Genetic contribution of polymorphism of the GLUT1 and GLUT4 genes to the susceptibility to type 2 (non-insulindependent) diabetes mellitus in different populations. Acta Diabetol 1996;33:193197.

95. Cox NJ, Xiang KS, Bell GI, Karam JH. Glucose transporter gene and non-insulindependent diabetes. Lancet 1988;2:793-794.

96. Alcolado JC, Baroni MG. Restriction fragment length polymorphisms at the GLUT4 and GLUT1 gene loci in type 2 diabetes. Diabet Med 1992;9:58-60.

97. Gutierrez C, Vendrell J, Pastor R, Broch M, et al. GLUT1 gene polymorphism in non-insulin-dependent diabetes mellitus: genetic susceptibility relationship with cardiovascular risk factors and microangiopathic complications in a Mediterranean population. Diabetes Res Clin Pract 1998;41:113-120.

98. Gibson F, Froguel P. Genetics of the APM1 locus and its contribution to type 2 diabetes susceptibility in French Caucasians. Diabetes 2004;53:2977-2983.

99. Gu HF, Abulaiti A, Ostenson CG, Humphreys K, et al. Single nucleotide polymorphisms in the proximal promoter region of the adiponectin (APM1) gene are associated with type 2 diabetes in Swedish Caucasians. Diabetes 2004;53(suppl 1):S31-S35.

100. Hara K, Boutin P, Mori Y, Tobe K, et al. Genetic variation in the gene encoding adiponectin is associated with an increased risk of type 2 diabetes in the Japanese population. Diabetes 2002;51:536-540.

101. Populaire C, Mori Y, Dina C, Vasseur F, et al. Does the -11377 promoter variant of APM1 gene contribute to the genetic risk for Type 2 diabetes mellitus in Japanese families? Diabetologia 2003;46:443-445.

102. Schwarz PE, Towers GW, Fischer S, Govindarajalu S, et al. Hypoadiponectinemia is associated with progression toward type 2 diabetes and genetic variation in the ADIPOQ gene promoter. Diabetes Care 2006;29:1645-1650.

103. Schwarz PE, Govindarajalu S, Towers W, Schwanebeck U, et al. Haplotypes in the promoter region of the ADIPOQ gene are associated with increased diabetes risk in a German Caucasian population. Horm Metab Res 2006;38:447-451.

104. Ukkola O, Santaniemi M, Rankinen T, Leon AS, et al. Adiponectin polymorphisms, adiposity and insulin metabolism: HERITAGE family study and Oulu diabetic study. Ann Med 2005;37:141-150.

105. Vasseur F, Helbecque N, Dina C, Lobbens S, et al. Single-nucleotide polymorphism haplotypes in the both proximal promoter and exon 3 of the APM1 gene modulate adipocyte-secreted adiponectin hormone levels and contribute to the genetic risk for type 2 diabetes in French Caucasians. Hum Mol Genet 2002;11:2607-2614.

106. Zacharova J, Chiasson JL, Laakso M. The common polymorphisms (single nucleotide polymorphism $[\mathrm{SNP}]+45$ and SNP +276 ) of the adiponectin gene predict the conversion from impaired glucose tolerance to type 2 diabetes: the STOPNIDDM trial. Diabetes 2005;54:893-899.

107. Ategbo JM, Grissa O, Yessoufou A, Hichami A, et al. Modulation of adipokines and cytokines in gestational diabetes and macrosomia. J Clin Endocrinol Metab. 20061; 91:4137-4143.

108. Heitritter SM, Solomon CG, Mitchell GF, Skali-Ounis N, et al. Subclinical inflammation and vascular dysfunction in women with previous gestational diabetes mellitus. J Clin Endocrinol Metab 2005;90:3983-3988.

109. Kinalski M, Telejko B, Kuzmicki M, Kretowski A, et al. Tumor necrosis factor alpha system and plasma adiponectin concentration in women with gestational diabetes. Horm Metab Res 2005;37:450-454.

110. Ranheim T, Haugen F, Staff AC, Braekke K, et al. Adiponectin is reduced in gestational diabetes mellitus in normal weight women. Acta Obstet Gynecol Scand 2004; 83:341-347.

111. Retnakaran R, Hanley AJ, Raif N, Hirning CR, et al. Adiponectin and beta cell dysfunction in gestational diabetes: pathophysiological implications. Diabetologia 2005;48:993-1001.

112. Retnakaran R, Hanley AJ, Raif N, Connelly PW, et al. Reduced adiponectin concentration in women with gestational diabetes: a potential factor in progression to type 2 diabetes. Diabetes Care 2004;27:799-800.

113. Thyfault JP, Hedberg EM, Anchan RM, Thorne OP, et al. Gestational diabetes is associated with depressed adiponectin levels. J Soc Gynecol Investig 2005;12:41-45.

114. Tsai PJ, Yu CH, Hsu SP, Lee YH, et al. Maternal plasma adiponectin concentrations at 24 to 31 weeks of gestation: negative association with gestational diabetes mellitus. Nutrition 2005;21:1095-1099.

115. Weerakiet S, Lertnarkorn K, Panburana P, Pitakitronakorn S, et al. Can adiponectin predict gestational diabetes? Gynecol Endocrinol 2006;22:362-368.

116. Williams MA, Qiu C, Muy-Rivera M, Vadachkoria S, et al. Plasma adiponectin concentrations in early pregnancy and subsequent risk of gestational diabetes mellitus. J Clin Endocrinol Metab 2004;89:2306-2311.

117. Winzer C, Wagner O, Festa A, Schneider B, et al. Plasma adiponectin, insulin sensitivity, and subclinical inflammation in women with prior gestational diabetes mellitus. Diabetes Care 2004;27:1721-1727.

118. Worda C, Leipold H, Gruber C, Kautzky-Willer A, et al. Decreased plasma adiponectin concentrations in women with gestational diabetes mellitus. Am J Obstet Gynecol 2004;191:2120-2124.

119. Katoh M, Katoh M. Human FOX gene family (Review). Int J Oncol 2004;25:14951500 .

120. Cederberg A, Gronning LM, Ahren B, Tasken K, et al. FOXC2 is a winged helix gene that counteracts obesity, hypertriglyceridemia, and diet-induced insulin resistance. Cell 2001;106:563-573.

121. Carlsson E, Groop L, Ridderstrale M. Role of the FOXC2-512C>T polymorphism in type 2 diabetes: possible association with the dysmetabolic syndrome. Int J Obes (Lond) 2005;29:268-274.

122. Fritsche A, Machicao F, Staiger H, Haring HU, et al. Lack of association between metabolic traits and the -512 polymorphism in FOXC2 in German people with normal glucose tolerance. Diabetologia 2004;47:756-757.

123. Yanagisawa K, Hingstrup LL, Andersen G, Drivsholm T, et al. The FOXC2$512 \mathrm{C}>\mathrm{T}$ variant is associated with hypertriglyceridaemia and increased serum Cpeptide in Danish Caucasian glucose-tolerant subjects. Diabetologia 2003;46: 1576-1580.

124. Kovacs P, Lehn-Stefan A, Stumvoll M, Bogardus C, et al. Genetic variation in the human winged helix/forkhead transcription factor gene FOXC2 in Pima Indians. Diabetes 2003;52:1292-1295.

125. Osawa H, Onuma H, Murakami A, Ochi M, et al. Systematic search for single nucleotide polymorphisms in the FOXC2 gene: the absence of evidence for the association of three frequent single nucleotide polymorphisms and four common haplotypes with Japanese type 2 diabetes. Diabetes 2003;52:562-567.

126. Fajans SS, Bell GI, Polonsky KS. Molecular mechanisms and clinical pathophysiology of maturity-onset diabetes of the young. N Engl J Med 2001;345:971-980.

127. Vaxillaire M, Froguel P. Genetic basis of maturity-onset diabetes of the young. Endocrinol Metab Clin North Am 2006;35:371-84, x.

128. Bonnycastle LL, Willer CJ, Conneely KN, Jackson AU, et al. Common variants in maturity-onset diabetes of the young genes contribute to risk of type 2 diabetes in Finns. Diabetes 2006;55:2534-2540.

129. Shaat N, Karlsson E, Lernmark A, Ivarsson S, et al. Common variants in MODY genes increase the risk of gestational diabetes mellitus. Diabetologia 2006;49:15451551.

130. Allan CJ, Argyropoulos G, Bowker M, Zhu J, et al. Gestational diabetes mellitus and gene mutations which affect insulin secretion. Diabetes Res Clin Pract 1997;36:135141.

131. Chiu KC, Go RC, Aoki M, Riggs AC, et al. Glucokinase gene in gestational diabetes mellitus: population association study and molecular scanning. Diabetologia 1994; 37:104-110. 


\section{Robitaille and Grant}

132. Lauenborg J, Damm P, Ek J, Glumer C, et al. Studies of the Ala/Val98 polymorphism of the hepatocyte nuclear factor-1alpha gene and the relationship to betacell function during an OGTT in glucose-tolerant women with and without previous gestational diabetes mellitus. Diabet Med 2004;21:1310-1315.

133. Zurawek M, Wender-Ozegowska E, Januszkiewicz-Lewandowska D, Zawiejska A, et al. GCK and HNF1alpha mutations and polymorphisms in Polish women with gestational diabetes. Diabetes Res Clin Pract 2007;76:157-158.

134. Medzhitov R, Janeway C Jr. Innate immunity. N Engl J Med 2000;343:338 -344.

135. Soell M, Lett E, Holveck F, Scholler M, et al. Activation of human monocytes by streptococcal rhamnose glucose polymers is mediated by CD14 antigen, and mannan binding protein inhibits TNF-alpha release. J Immunol 1995;154:851-860.

136. Kilpatrick DC. Mannan-binding lectin: clinical significance and applications. Biochim Biophys Acta 2002;1572:401-413.

137. Garred P, Thiel S, Madsen HO, Ryder LP, et al. Gene frequency and partial protein characterization of an allelic variant of mannan binding protein associated with low serum concentrations. Clin Exp Immunol 1992;90:517-521.

138. Madsen HO, Garred P, Thiel S, Kurtzhals JA, et al. Interplay between promoter and structural gene variants control basal serum level of mannan-binding protein. J Immunol 1995; 155:3013-3020.

139. Sumiya M, Super M, Tabona P, Levinsky RJ, et al. Molecular basis of opsonic defect in immunodeficient children. Lancet 1991;337:1569-1570.

140. Hansen TK, Tarnow L, Thiel S, Steffensen R, et al. Association between mannosebinding lectin and vascular complications in type 1 diabetes. Diabetes 2004;53: $1570-1576$.

141. Megia A, Gallart L, Fernandez-Real JM, Vendrell J, et al. Mannose-binding lectin gene polymorphisms are associated with gestational diabetes mellitus. J Clin Endocrinol Metab 2004;89:5081-5087.

142. Saido TC, Sorimachi H, Suzuki K. Calpain: new perspectives in molecular diversity and physiological-pathological involvement. FASEB J 1994;8:814-822.

143. Patel YM, Lane MD. Role of calpain in adipocyte differentiation. Proc Natl Acad Sci US A 1999;96:1279-1284.

144. Smith LK, Rice KM, Garner CW. The insulin-induced down-regulation of IRS-1 in 3T3-L1 adipocytes is mediated by a calcium-dependent thiol protease. Mol Cell Endocrinol 1996;122:81-92.

145. Horikawa Y, Oda N, Cox NJ, Li X, et al. Genetic variation in the gene encoding calpain-10 is associated with type 2 diabetes mellitus. Nat Genet 2000;26:163-175.
146. Weedon MN, Schwarz PE, Horikawa Y, Iwasaki N, et al. Meta-analysis and a large association study confirm a role for calpain-10 variation in type 2 diabetes susceptibility. Am J Hum Genet 2003;73:1208-1212.

147. Leipold H, Knofler M, Gruber C, Haslinger P, et al. Calpain-10 haplotype combination and association with gestational diabetes mellitus. Obstet Gynecol 2004;103: $1235-1240$.

148. Feinbloom D, Bauer KA. Assessment of hemostatic risk factors in predicting arterial thrombotic events. Arterioscler Thromb Vasc Biol 2005;25:2043-2053.

149. Correia ML, Haynes WG. A role for plasminogen activator inhibitor-1 in obesity: from pie to PAI? Arterioscler Thromb Vasc Biol 2006;26:2183-2185.

150. Alessi MC, Bastelica D, Morange P, Berthet B, et al. Plasminogen activator inhibitor 1, transforming growth factor-beta1, and BMI are closely associated in human adipose tissue during morbid obesity. Diabetes 2000;49:1374-1380.

151. Festa A, D'Agostino R Jr, Tracy RP, Haffner SM. Elevated levels of acute-phase proteins and plasminogen activator inhibitor-1 predict the development of type 2 diabetes: the insulin resistance atherosclerosis study. Diabetes 2002;51:1131-1137.

152. Eriksson P, Kallin B, van 't Hooft FM, Bavenholm P, et al. Allele-specific increase in basal transcription of the plasminogen-activator inhibitor 1 gene is associated with myocardial infarction. Proc Natl Acad Sci U S A 1995;92:1851-1855.

153. Berberoglu M, Evliyaoglu O, Adiyaman P, Ocal G, et al. Plasminogen activator inhibitor-1 (PAI-1) gene polymorphism ( -675 4G/5G) associated with obesity and vascular risk in children. J Pediatr Endocrinol Metab 2006;19:741-748.

154. Bouchard L, Mauriege P, Vohl MC, Bouchard C, et al. Plasminogen-activator inhibitor-1 polymorphisms are associated with obesity and fat distribution in the Quebec Family Study: evidence of interactions with menopause. Menopause 2005; 12:136-143.

155. Leipold H, Knoefler M, Gruber C, Klein K, et al. Plasminogen activator inhibitor 1 gene polymorphism and gestational diabetes mellitus. Obstet Gynecol 2006;107: 651-656.

156. Li LS, Lonnqvist F, Luthman H, Arner P. Phenotypic characterization of the Trp64Arg polymorphism in the beta 3-adrenergic receptor gene in normal weight and obese subjects. Diabetologia 1996;39:857-860.

157. Stone LM, Kahn SE, Fujimoto WY, Deeb SS, et al. A variation at position -30 of the beta-cell glucokinase gene promoter is associated with reduced beta-cell function in middle-aged Japanese-American men. Diabetes 1996;45:422-428. 